\title{
Context-dependent fruit-frugivore interactions: partner identities and spatio-temporal variations
}

\author{
Ramón Perea, Miguel Delibes, Mark Polko, Alberto Suárez-Esteban and José M. Fedriani \\ R. Perea (ramon.perea@upm.es), Depto de Silvopascicultura, ETSI, Montes, Univ. Politécnica de Madrid, Ciudad Universitaria s/n, \\ ES-28040 Madrid, Spain. - M. Delibes, M. Polko, A. Suárez-Esteban and J. M. Fedriani, Depto de Biología de la Conservación, \\ Estación Biológica de Doñana (EBD-CSIC), Avda. Américo Vespucio s/n, ES-41092 Sevilla, Spain. JMF also at: Dept of Ecological Modelling, \\ Helmholtz Centre for Environmental Research GmbH - UFZ, Permoserstrasse 15, DE-04318 Leipzig, Germany.
}

\begin{abstract}
Fruit-frugivore interactions are crucial for the dynamics and regeneration of most forested ecosystems. Still, we lack an understanding of the potential variation in the sign and strength of such interactions in relation to variations in the spatial and temporal ecological context. Here, we evaluated spatial (three sites) and temporal (two fruiting seasons) local variation in the sign (seed predation versus dispersal) and strength (frequency and quantity) of the interactions among six frugivorous mammals and a community of Mediterranean fleshy-fruited shrubs. We examined mammal faecal samples and quantified frequency of seed occurrence, number of seeds per faecal sample, seed species diversity and quality of seed treatment (i.e. percentage of undamaged seeds). The frequency of seed occurrence and number of seeds per faecal sample strongly varied among dispersers, sites, seasons and fruit species. For instance, fox Vulpes vulpes faeces showed between 6 and 40 times more seeds than wild boar Sus scrofa faeces in seasons or sites in which Rubus and Juniperus seeds were dominant. However, in seasons or sites dominated by Corema seeds, wild boar faeces contained up to seven times more seeds than fox faeces. Mammalian carnivores (fox and badger, Meles meles) treated seeds gently, acting mostly as dispersers, whereas deer (Cervus elaphus and Dama dama) acted mainly as seed predators. Interestingly, rabbit Oryctolagus cuniculus acted as either mostly seed disperser or seed predator depending on the plant species. Our results indicated that the sign of fruit-frugivore interactions depended mainly on the identity of the partners. For a particular fruit-frugivore pair, however, our surrogate of interaction strength largely varied with the spatio-temporal context (year and habitat), leading to a low specificity across the seed-frugivore network. The high spatio-temporal variability of seed dispersal (in quantity, quality and seed diversity) by different frugivores would confer resilience against unpredictable environmental conditions, such as those typical of Mediterranean ecosystems.
\end{abstract}

Context dependence of species interactions in terms of both strength and outcome is now recognized as a key area of study for advancing population and community ecology (Agrawal et al. 2007, Holland and DeAngelis 2009). Context dependence is often analyzed at two different levels. At a coarse level, the specific identity of partners involved in an interaction can determine its sign, i.e. its position along the mutualism-antagonism continuum (Karst et al. 2008, Chamberlain and Holland 2009). At a finer level and for a given pair of species, the spatial and temporal variations in the biotic and abiotic conditions can lead to context dependence of the strength and sign of the interaction (Bronstein 1994, Thompson et al. 2001, Holland and Bronstein 2008). Although context dependence is thought to characterize most species interactions, recent metaanalyses question this point (Karst et al. 2008, Chamberlain and Holland 2009) and, thus, further evaluations in contrasting species relationships are clearly desirable.

Fleshy fruits are commonly consumed by a wide assemblage of frugivores, each of which consumes a subset of the available fruits that overlaps slightly or greatly with the subsets consumed by other frugivores in the assemblage (Howe and Smallwood 1982, Herrera 2002, Dennis et al. 2007). Such generalized interactions can range from antagonism (i.e. seed predation) to mutualism (i.e. seed dispersal). Furthermore, when an interaction results mostly in seed dispersal, it is usually characterized by great variation in both the quantity (number of seeds dispersed) and quality (e.g. seed treatment and aggregation, microsite of deposition) of dispersal, and hence in overall dispersal effectiveness (Schupp et al. 2010). An important portion of this variation is related to the biotic and abiotic context (Schupp et al. 2010). However, despite the recent commendable research effort on fruit-frugivore interactions (Levey et al. 2002, Dennis et al. 2007, Jordano et al. 2011), few analyses have evaluated the influence of partner identity and spatialtemporal variations on the sign and strength of fruitfrugivore interactions in a given community (but see Carlo et al. 2003).

Frugivore species, plant species, species-specific crop size, availability of alternative food and habitat structure are examples of factors that vary spatially and temporally, even at 
the local scale (Jordano 1994, Carlo et al. 2007, Perea et al. 2011). Although seed fate has been extensively studied as a whole process (from fruit ingestion to seedling establishment), most studies have not considered the spatio-temporal variation at local level within the assemblage of fruit-bearing plants and frugivores. Thus, studies at different times and locations are essential to assess the sign of fruit-frugivore interactions and, when appropriate, the effectiveness of seed dispersal (Wang and Smith 2002, Carlo et al. 2003, Hampe et al. 2008, Carlo and Yang 2011). This would help to quantify the strength of the interactions in large assemblages, which has been traditionally considered a major limitation on species interaction networks (Berlow et al. 2004, Vázquez et al. 2005). Many quantitative estimates of interaction strength have been proposed (Laska and Wootton 1998, Wootton and Emmerson 2005), including the frequency of interaction, which has been used as a successful surrogate of interaction strength (Vázquez et al. 2005). However, whether the spatio-temporal variation affects the frequency of the interactions and, eventually, the patterns of interaction strength remains elusive and needs further attention.

In this study we evaluate the relative importance of partner identity and spatial-temporal variations on the sign and strength of fruit-frugivore interactions within a diverse community of fleshy-fruited plants consumed by an assemblage of six frugivorous mammals. Mammal species differ in many relevant traits (e.g. body size, mobility, gut characteristics, foraging behavior and food preferences), which may influence seed treatment and thus the sign of the interaction. Furthermore, even when the interaction is mostly mutualistic (i.e. leading to effective seed dispersal), mammals can differ in quantitative and qualitative components of their dispersal effectiveness (Schupp 1993, Brodie et al. 2009). For instance, mammal faeces may contain seeds at different densities and survival probabilities as a result of the animal species involved (Traveset and Verdú 2002, Jordano et al. 2007) and the chemical and physical fruit and seed properties (Murray et al. 1994, Verdú and Traveset 2004, Traveset et al. 2008). In addition, the environmental context may be an important source of variation in seed abundance, diversity and survival in mammal faeces (Traveset et al. 2001, Matías et al. 2010, Tsuji et al. 2011). Hence, faeces, which usually contain a variety of seeds, might hamper or facilitate seed survival, germination and seedling establishment, depending on how many seeds are found in each faeces, what proportion of them remains undamaged, and the heterogeneity of seed types and species (seed diversity).

To assess the relative importance of both levels of context dependence (i.e. the identity of interacting species and the biotic and abiotic environment) in our fruit-frugivore network, we considered a total of 31 fruit-frugivore pairs during two dispersal seasons and in three sites at southwestern Spain. We quantify the following aspects of mammal dispersal effectiveness: 1) the proportion of faeces containing seeds; 2) the number of seeds per faecal sample; 3) the seed species diversity within each faecal sample, and 4) based on mammal seed treatment, we estimated whether each particular interaction is mostly mutualistic, mostly antagonistic, or a mixture of both. We hypothesized that the sign of fruit-frugivore interactions will be mostly determined by the identity of interacting species whereas the interaction strength (i.e. frequency of seed occurrence and number of dispersed seeds) of each particular fruit-frugivore pair will vary largely in space and time, even at the local level of our study.

\section{Material and methods}

\section{Study area and sites}

The study was carried out during the dispersal seasons (September-February) of 2005-2006 and 2006-2007 in the Doñana National Park $\left(510 \mathrm{~km}^{2} ; 37^{\circ} 9^{\prime} \mathrm{N}, 6^{\circ} 26^{\prime} \mathrm{W}\right.$; elevation 0-80 $\mathrm{m}$ a.s.l.), southwestern Spain. The climate is Mediterranean sub-humid, characterized by hot and dry summers (June-September) and mild, wet winters (OctoberJanuary). The annual precipitation varies widely, ranging between $170-1028 \mathrm{~mm}(\mathrm{mean} \pm \mathrm{SD}=583.0 \pm 221.1 \mathrm{~mm}$; $\mathrm{n}=25$ years). During our study, overall rain in the second meteorological year (i.e. from September 2006 to August 2007; $716.9 \mathrm{~mm}$ ) was 1.5 -fold higher than that during the first year $(468.3 \mathrm{~mm})$. The Doñana area is characterized by two main environments: scrubland and marshland. The marshland remains flooded a portion of the year and it is not relevant for this study. The scrubland area, on sandy soils, is made up of patchy, heterogeneous landscapes with a great variety of different habitats and plant communities.

Because the community of fleshy-fruited shrubs in Doñana largely differs among habitats, we selected three sites (separated $\geq 7.4 \mathrm{~km}$ from each other) within the scrubland area of the National Park, inside the areas called Matasgordas, Vera, and Sabinar. 1) The Matasgordas site is dominated by the evergreen shrub Pistacea lentiscus growing alone or in small clumps, separated by unvegetated space or a sparse understory of Halimium halimifolium, Ulex spp., Cistus spp., Olea europaea var. sylvestris, Phillyrea angustifolia, Chamaerops bumilis and Myrtus communis, together with some scattered trees, mainly Quercus suber and Pyrus bourgaeana. 2) The Vera site is a shrubby landscape, near the marsh border, dominated by Ulex spp. and Halimium halimifolium. There are also several fleshy-fruited species such as Rubus ulmifolius, Chamareops humilis and Pyrus bourgaeana trees. Quercus suber trees are also scattered across the area. 3) The Sabinar site is located in a dune area dominated by Juniperus phoenicea subsp. turbinata and Juniperus oxycedrus subsp. macrocarpa $(\mathrm{Sm}$.) Ball with an understory of Corema album, Ulex spp., Rubus ulmifolius and Halimium halimifolium. Also Pinus pinea trees are common.

\section{Study species}

We studied six fruit-eating mammal species which differed in body size, mobility, diet and faecal marking behaviour: red and fallow deer, Cervus elaphus and Dama dama (40-80 kg at the study area, herbivores), hereafter considered as a functional taxon: deer, wild boar, Sus scrofa (40-50 kg, omnivore), European rabbit, Oryctolagus cuniculus $(0.8-1.0 \mathrm{~kg}$, herbivore) and two carnivores with generalist feeding habits (European badger Meles meles $(6-8 \mathrm{~kg})$ and red fox Vulpes vulpes $(5-7 \mathrm{~kg}))$. Other carnivores present in the study 
area are the Egyptian mongoose Herpestes ichneumon and the common genet Genetta genetta, but they rarely consume fruits (Palomares and Delibes 1991). Another carnivorous species is the Iberian lynx Lynx pardinus, which feeds almost exclusively on rabbits (Delibes 1980).

We considered eight fleshy-fruited plant species whose fruits are most frequently consumed by mammals. Among one-seeded drupes, $C$. humilis is the heaviest $(1.71 \mathrm{~g}$ fresh fruit mass, $669 \mathrm{mg}$ dry seed mass), followed by O. europaea (0.62 g, $221 \mathrm{mg}$ dry seed mass) and P. lentiscus $(0.10 \mathrm{~g}$, $25 \mathrm{mg}$ dry seed mass). Another drupe (multi-seeded) is R. ulmifolius $(0.73 \mathrm{~g}$ fresh fruit mass, 28.8 seeds per fruit, $2 \mathrm{mg}$ dry seed mass). Among berries, $M$. communis is the largest one $(0.39 \mathrm{~g}$ fresh fruit mass, 7.5 seeds per fruit, $5 \mathrm{mg}$ dry seed mass) followed by C. album (0.16 g, 3.0 seeds per fruit, $10 \mathrm{mg}$ dry seed mass). Pyrus bourgaeana was the only pome-bearing species (6.75 g fresh fruit mass, 7.9 seeds per fruit, $30 \mathrm{mg}$ dry seed mass). Among galbuli (juniper fruits) we found $J$. oxycedrus $(0.47 \mathrm{~g}, 1.5$ seeds per fruit, $62 \mathrm{mg}$ dry seed mass) and J. phoenicea (0.22 g, 7.5 seeds per fruit, $47 \mathrm{mg}$ dry seed mass; all data from Jordano 2007). Fruit ripening and seed dispersal period of these species occur from late summer to early winter and there are no marked different phenological patterns among study sites (Fedriani and Delibes 2009a). Furthermore, our sampling encompassed most of the ripening and dispersal seasons of target plants; thus, our extensive dataset allowed for rigorous spatial and temporal comparisons. Most target plant species rely mainly on mammals for seed dispersal (Fedriani and Delibes 2009a), though $R$. ulmifolius and J. phoenicea also include birds as important seed dispersers (Jordano 1984).

\section{Methods}

We collected mammal faeces during two consecutive seasons (from September to February of years 2005-2007) in the three study sites. In each site, we searched for faeces weekly during both seasons and within similar sized plots (72.0, 98.6 and 81.1 ha in Matasgordas, Vera and Sabinar, respectively). To ensure that samples were representative of each site, we established between 11 and 13 starting points distributed regularly along the plot edges. Each observer followed a non-regular zig-zag path from a starting point to a non-fixed point on the opposite side of the plot. Then, the observer returned back to the original side following a different path (Fedriani et al. 2010). Each survey took about $2 \mathrm{~h}$ and a total of 100 surveys were made for each site (i.e. 600 observer-hours in total). Attempting to balance sample sizes per frugivore and survey, we collected all fox and badger faeces we found (which are locally scarce) but only up to the first five deer and boar faecal samples (which are relatively abundant in the area). We collected up to 20 pellets per deer faecal group since one deer defecation contains an average of 19 pellets (Tottewitz et al. 1996). For the abundant rabbit, we only performed surveys monthly and up to 30 samples per survey were collected (20 droppings per sample). We could not collect deer faeces during the first season for logistic reasons. The amount of faecal samples per site and season varied between 77 and 93 for deer, 29 and 88 for wild boar, 1 and 90 for red fox, 2 and 118 for badger and, 20 and 150 for rabbit. Samples were individually stored and air dried in paper bags at room temperature.

Each sample was washed carefully using a sieve (mesh size $0.5 \mathrm{~mm}$ ) under running water. All seeds and parts of them (skin, pulp, pedicels, etc.) were separated and identified using 20-40× magnifying glasses and a reference sample. The number of intact and damaged seeds (crushed or fractured) was recorded. Special care was taken to detect seed coat remains which were used to estimate the total amount of seeds ingested (Herrera 1989). The frequency of seed occurrence in mammal faeces was calculated as: (number of faecal samples with seeds/total number of samples). The proportion of undamaged seeds per faeces was estimated as: (number of seeds with no apparent physical damage/total number of seeds in a faecal sample). Based on this index, we estimated where each mammal-plant interaction falls within the continuum between antagonism (the proportion of undamaged seeds close to zero) and mutualism (the proportion of undamaged seeds close to one). Intermediate values (say, $0.4-0.6$ ) would indicate a mixture of antagonism and mutualism and, for these pairs of species, the net effect of their interactions seem particularly likely to be context-dependent. We calculated the Shannon diversity equitability index (Begon et al. 1996) for each faeces containing seeds as follows: HE (Shannon equitability index $\left.)=\left(-\sum \mathrm{p}_{\mathrm{i}} \ln \mathrm{p}_{\mathrm{i}}\right) / \ln S\right)$, where $\mathrm{p}_{\mathrm{i}}$ is the proportion of seeds from species i relative to the total number of seeds in a faecal sample and $S$ is the seed species richness (total number of species). Thus, seed diversity is a proportion (value from 0 to 1 ) of the highest possible diversity of seeds found in a faecal sample.

\section{Data analysis}

To evaluate differences in the frequency of seed occurrence, we fitted a generalized linear model (GLM) where the response variable was binary (excrement containing seeds or not, independently of plant species; binomial error family) and the fixed effects were 'mammal species', 'site', 'season' and all their possible interactions. Then, to evaluate the differences in the number of seeds per excrement we ran another GLM with count data (Poisson error family). Only faeces containing seeds were included in the model. The response variable was the total number of seeds found in each faecal sample. Fixed effects were the same as in the model above plus 'Dominant plant species' (hereafter DPS), defined as the most abundant seed species in a faecal sample. Based on their fruit and seed traits, we expected that for some DPS (e.g. $R$. ulmifolius) the overall number of seeds in the faecal sample would be typically large, whereas for other DPS (e.g. C. humilis) such metric would be usually small. However, the spatial and temporal consistence of such trend could depend of many factors, such as the composition of the local plant community. Only two-way interactions were considered in the model due to lack of convergence of the saturated model. To analyze the diversity of seeds (Shannon equitability index) in faeces we ran another GLM (binomial error family) with seed diversity as response variable and the next fixed effects: mammal species, site, season, number of seeds per excrement and all two-way interactions among factors. Finally, to test for the differences in the proportion of undamaged 
Table 1. Summary of the data obtained from the faecal samples collected during two consecutive seasons for the three sites. Seed diversity has been calculated as the Shannon equitability index $(\mathrm{EH})$.

\begin{tabular}{lcccccc}
\hline Mammal species & $\begin{array}{c}\text { No. of faecal } \\
\text { samples }\end{array}$ & $\begin{array}{c}\text { Total no. } \\
\text { of seeds }\end{array}$ & $\begin{array}{c}\text { Frequency of } \\
\text { seed occurrence } \\
\text { in faeces }(\%)\end{array}$ & $\begin{array}{c}\text { No. of seeds per } \\
\text { faecal sample } \\
\text { (Mean } \pm \text { S D) }\end{array}$ & $\begin{array}{c}\text { Proportion of undamaged } \\
\text { seeds per faecal sample } \\
(\% \pm \text { SD) }\end{array}$ & $\begin{array}{c}\text { Seed diversity } \\
\text { (EH } \pm \text { SD) }\end{array}$ \\
\hline Rabbit Oryctolagus cuniculus & 556 & 10919 & 16.5 & $40.9 \pm 70.7$ & $69.6 \pm 39.9$ & $0.14 \pm 0.23$ \\
Badger Meles meles & 252 & 145484 & 60.3 & $959.6 \pm 2868.9$ & $86.5 \pm 24.4$ & $0.08 \pm 0.19$ \\
Red fox Vulpes vulpes & 192 & 90873 & 57.8 & $818.7 \pm 1012.2$ & $96.0 \pm 0.09$ & $0.01 \pm 0.07$ \\
Deer Cervus/Dama & 251 & 381 & 12.4 & $12.4 \pm 16.6$ & $52.7 \pm 31.4$ & $0.02 \pm 0.11$ \\
Wild boar Sus scrofa & 345 & 35641 & 29.0 & $356.4 \pm 680.2$ & $79.3 \pm 24.0$ & $0.03 \pm 0.10$ \\
\hline
\end{tabular}

seeds (seeds with no apparent physical damage after gut passage) we fitted another GLM with binomial error family. The response variable was the proportion of undamaged seeds in each faecal sample. Fixed effects were the same as in the first model (mammal species, site and season) plus 'Dominant damaged plant species', hereafter DDPS. Dominant damaged plant species was defined as the species with highest number of physically damaged seeds in each faecal sample. All two-way interactions among factors were considered. All models were performed using the R 2.11.1 free software ( $<$ www.r-project.org $>$ ). Missing values were treated as NA (not available) in the R software. For all GLM, we checked for overdispersion and used quasi-likelihood to specify a more appropriate variance function in order to achieve valid analysis (Crawley 2007, Zuur et al. 2009).

\section{Results}

\section{Frequency of seed occurrence in faeces}

A total of 283298 seeds were recovered from 1596 collected faecal samples (Table 1 ). Seeds from $R$. ulmifolius were found in a much higher proportion $(85.9 \%$ of total number of seeds; $33.4 \%$ of faecal samples with seeds contained Rubus seeds), followed by C. album (12.6\% of total number of seeds; $45.5 \%$ of faecal samples with seeds). Furthermore, both seed species were found in samples of all frugivore species. Other less frequent plant species in faecal samples were J. phoenicea (22.5\% of faecal samples with seeds), P. bourgaeana (12.2\%), C. humilis (8.9\%), P. lentiscus (4.7\%), M. communis $(1.9 \%)$ and J. oxycedrus (1.1\%). Target frugivores consumed most studied fruiting plants, being deer the species with lowest range of species consumption (two species with more than $5 \%$ of frequency in faeces) and badger with the highest (five species with more than 5\%).

As predicted by our hypothesis, the frequency of seed occurrence in faeces varied strongly among mammal species, sites and seasons (Table 2). Carnivores (badger and red fox) showed the highest frequency of faeces containing seeds, followed by wild boar, rabbit and deer (Table 1). There was a significant second order interaction between site and mammal species, indicating that the frequency of seed occurrence among frugivores varied inconsistently among sites (Table 2, Fig. 1). We also found a significant site-season interaction in the frequency of seed occurrence (Table 2). For example, whereas in site Matasgordas there was a higher proportion of faeces containing seeds at the first season, in site Sabinar we found a higher proportion at the second season
(Fig. 1). However, there was also a third order interaction among mammal species, site and season (Table 2), indicating that the frequency of seed occurrence was inconsistent among frugivore species and, in turn, was simultaneously inconsistent across sites and seasons. For example, badger showed much higher frequency of seed occurrence than rabbit during both seasons in Matasgordas and only in the first season in Vera, and lower or similar frequencies for both seasons in Sabinar (Fig. 1).

\section{Number of seeds per faecal sample}

Faeces contained a highly variable number of seeds across the studied mammals, varying from a mean of about 12 seeds (deer) to more than 950 seeds per faecal sample (badger; Table 1). Interestingly, the number of seeds per excrement for each frugivore also varied inconsistently across the three sites (i.e. there was a significant animalsite interaction; Table 3). Thus, faecal samples of badger contained the highest number of seeds in Matasgordas and Vera, whereas in Sabinar more seeds per faeces were found in wild boar faeces (Fig. 2a). We also found a significant site-dominant plant species (DPS) interaction (Table 3), indicating that the number of seeds per faecal sample was dependent on the DPS but in an inconsistent manner across study sites (Fig. 2a). For example, in Vera, the highest mean number of seeds was found in faeces containing mostly R. ulmifolius seeds, whereas in Sabinar the highest mean number of seeds was archived for C. album-dominated faeces (Fig. 2a).

In addition, we found a significant interaction between mammal species and the DPS in the number of seeds per excrement (Table 3). For example, fox faeces showed 6 and 40 times more seeds than wild boar faeces when $R$. ulmifolius and J. phoenicea were, respectively, the DPS.

Table 2. Summary of the GLM model to test for the differences in the occurrence of seeds in faeces. Bold type indicates statistical significance $(p<0.05)$.

\begin{tabular}{lrrr}
\hline Fixed effects & \multicolumn{1}{c}{$\chi^{2}$} & DF & p-value \\
\hline Mammal species & 228.06 & 4 & $<\mathbf{0 . 0 0 1}$ \\
Site & 357.40 & 2 & $<\mathbf{0 . 0 0 1}$ \\
Season & 20.28 & 1 & $<\mathbf{0 . 0 0 1}$ \\
Mammal species $\times$ Site & 167.89 & 9 & $<\mathbf{0 . 0 0 1}$ \\
Mammal species $\times$ Season & 3.34 & 3 & 0.342 \\
Site $\times$ Season & 12.46 & 2 & $\mathbf{0 . 0 0 2}$ \\
Mammal species $\times$ Site $\times$ Season & 17.05 & 6 & $\mathbf{0 . 0 0 9}$
\end{tabular}

Deviance explained: 40.7\%; Dispersion: 0.81; AIC: 1328. 

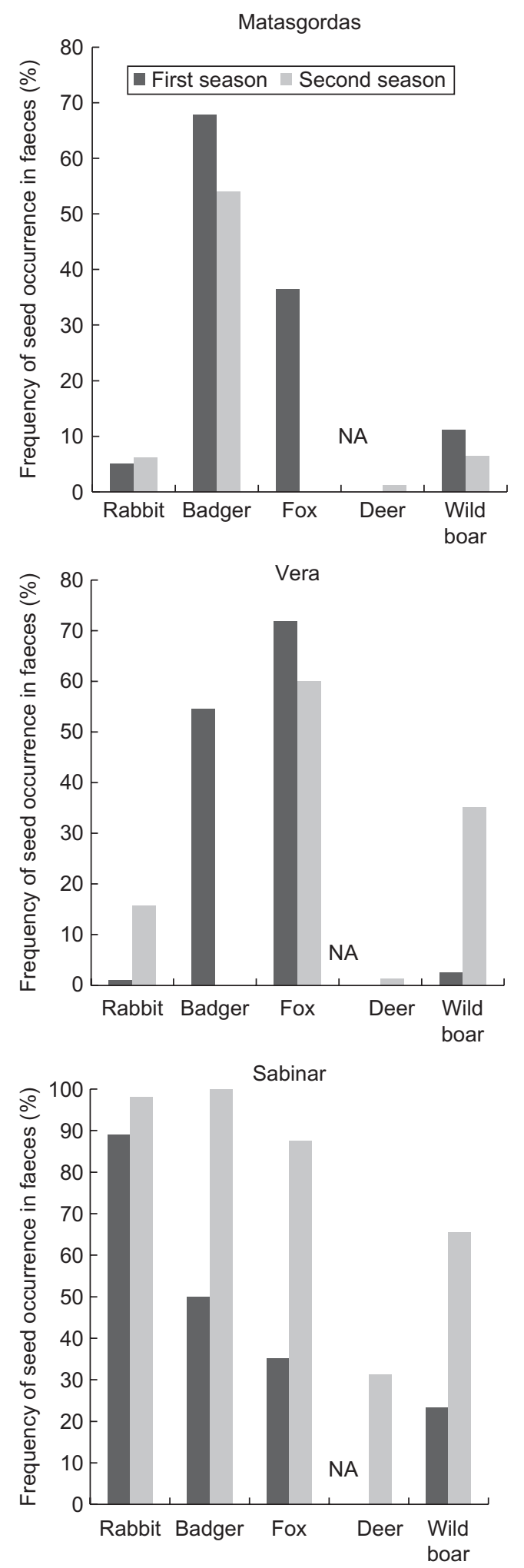

Figure 1. Frequency of seed occurrence in faeces ((number of faecal samples with seeds/total number of samples $) \times 100)$ for the interaction between mammal species, sites and dispersal seasons. NA indicates no data available for deer in year 2005.

Conversely, wild boar samples contained seven times higher number of seeds than fox samples when $C$. album was the DPS (Fig. 2b). As a whole, these results indicate that speciesspecific foraging and fruit preferences make the number of
Table 3. Summary of the GLM model to test for the differences in the number of seeds per excrement. Bold type indicates statistical significance $(p<0.05)$.

\begin{tabular}{lrrr}
\hline Fixed effects & \multicolumn{1}{c}{$\chi^{2}$} & DF & p-value \\
\hline Mammal species & 292.40 & 4 & $\mathbf{< 0 . 0 0 1}$ \\
Dominant plant species (DPS) & 44.17 & 7 & $\mathbf{< 0 . 0 0 1}$ \\
Site & 34.59 & 2 & $<\mathbf{0 . 0 0 1}$ \\
Season & 1.32 & 1 & 0.251 \\
Mammal species $\times$ DPS & 42.89 & 12 & $\mathbf{< 0 . 0 0 1}$ \\
Mammal species $\times$ Site & 20.31 & 6 & $\mathbf{< 0 . 0 0 1}$ \\
Mammal species $\times$ Season & 1.42 & 3 & 0.701 \\
DPS $\times$ Site & 16.24 & 6 & $<\mathbf{0 . 0 0 1}$ \\
DPS $\times$ Season & 10.88 & 4 & $\mathbf{0 . 0 2 8}$ \\
Site $\times$ Season & 0.064 & 2 & 0.799 \\
\hline
\end{tabular}

Deviance explained: 70.4\%; Dispersion: 0.80; AIC: 6879.

seeds per faecal sample rather dependent on the particular identities of interacting plant and animal partners.

\section{Seed diversity in faeces}

Seed diversity significantly varied across sites (Table 4) with higher values for Sabinar $(\mathrm{EH}=0.148 \pm 0.012, \mathrm{n}=330)$, closely followed by Matasgordas $(\mathrm{EH}=0.102 \pm 0.019$, $\mathrm{n}=121)$, and with much lower values for Vera $(\mathrm{EH}=$ $0.004 \pm 0.002, \mathrm{n}=171)$, matching the fruit diversity of the study sites (unpubl.). Significant differences were found among mammal species (Table 4), with higher seed diversity for faeces from rabbit and badger as compared with those from deer, red fox and wild boar (Table 1). Number of seeds per excrement and seed diversity (Shannon equitability index) were negatively correlated $\left(\mathrm{R}^{2}=-0.24 ; t=-3.485\right.$; $\mathrm{p}=0.005)$. An increasing number of seeds per excrement caused a decrease in seed diversity with a logarithmic trend line (Fig. 3). There were no significant interactions among main factors for seed diversity $(\mathrm{p}>0.301)$, indicating that this aspect of mammal seed dispersal was rather consistent in space and time.

\section{Proportion of undamaged seeds in faeces}

The overall proportion of undamaged seeds in faeces varied from $52.7 \%$ for deer to $96.0 \%$ for red fox (Table 1), and these interspecific differences were highly significant $\left(\chi_{4}^{2}=35.40, \mathrm{p}<0.001\right)$. Dominant damaged plant species (DDPS), season and site did not have an effect as main factors on the proportion of undamaged seeds. However, the interaction between season and DDPS was significant $\left(\chi_{4}^{2}=15.48, \mathrm{p}=0.004\right)$. This was related to the fact that $P$. lentiscus and $M$. communis seeds were damaged more frequently during the first season $(81 \%$ and $96 \%$, respectively) as compared with the second season $(37 \%$ and $74 \%$, respectively). Other second-order interactions were not significant $(\mathrm{p}>0.462)$.

To evaluate in detail whether the percentage of undamaged seeds was dependent on the particular frugivore-plant pair, we performed an analysis for each frugivore species separately. We found that, for rabbit, the proportion of undamaged seeds in faeces significantly varied among plant species $\left(\chi^{2}=14.93, \mathrm{p}=0.011\right)$, with $C$. album showing the highest percentage of undamaged seeds $(93.3 \%, \mathrm{n}=1801$ seeds) as opposed to $P$. bourgaeana which had the lowest 
(a)
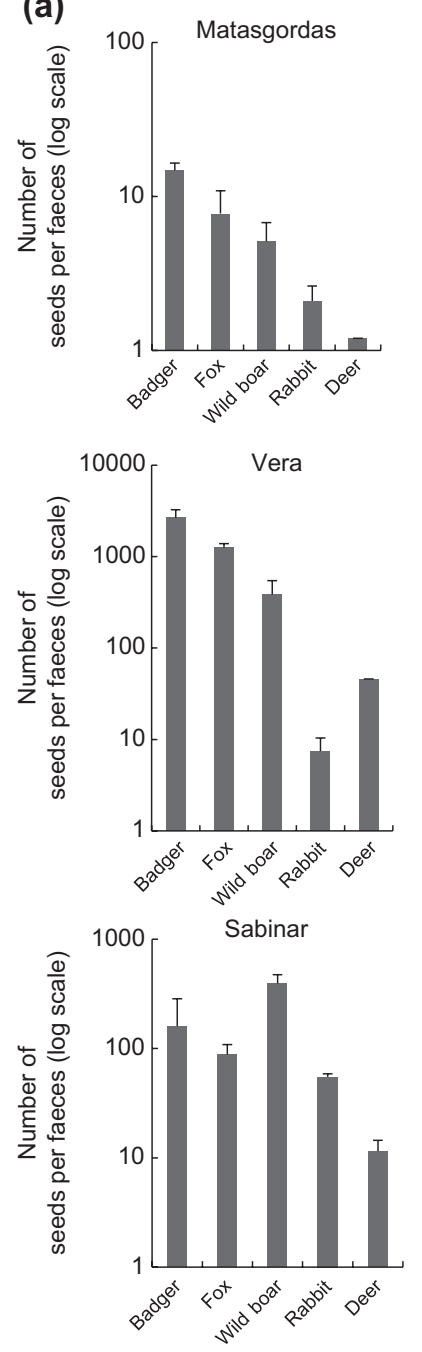

(b)

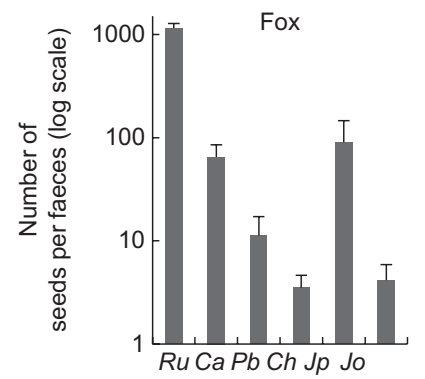

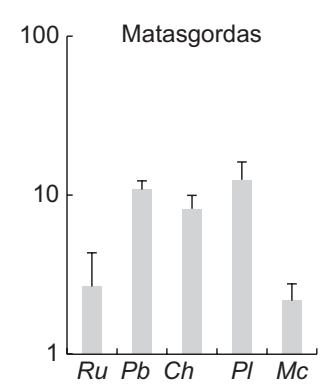
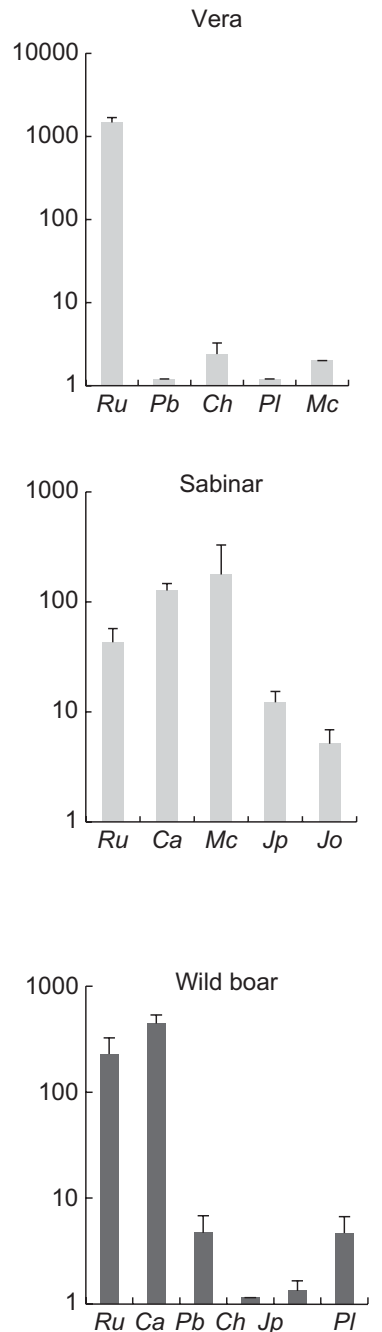

Figure 2. Mean $( \pm S E)$ number of seeds per faecal sample for the different frugivorous species, sites and dominant plant species (the most abundant plant species in each faecal sample). (a) Data are shown for sites in relation to mammal species (black bars) and plant species (gray bars). (b) Data are shown for fox and wild boar as examples of the interaction between mammal species and dominant plant species. $C a=C$. album; $C h=C$. humilis; $J o=$ $J$. oxycedrus; $J p=J$. phoenicea; $M c=M$. communis; $P b=P$. bourgaeana; $P l=P$. lentiscus; $R u=R$. ulmifolius.

percentage (0.0\%, $n=26$; Fig. 4). For badger, red fox, deer and wild boar we found no significant effect, indicating that the percentage of undamaged seeds was rather consistent across plant species. The lack of significant difference across

Table 4. Summary of the GLM model to test for the differences in the diversity of seeds per excrement. Bold type indicates $p<0.05$.

\begin{tabular}{lrrr}
\hline Fixed effects & \multicolumn{1}{c}{$\chi^{2}$} & DF & $p$-value \\
\hline Mammal species & 29.35 & 4 & $<\mathbf{0 . 0 0 1}$ \\
Site & 22.66 & 2 & $<\mathbf{0 . 0 0 1}$ \\
Season & 0.01 & 1 & 0.932 \\
Number of seeds per excrement & 4.70 & 1 & $\mathbf{0 . 0 3 0}$ \\
Mammal species $\times$ Site & 2.31 & 9 & 0.986 \\
Mammal species $\times$ Season & 3.66 & 3 & 0.301 \\
Mammal species $\times$ Number of seeds & 1.12 & 5 & 0.952 \\
Site $\times$ Season & 0.05 & 2 & 0.974 \\
Site $\times$ Number of seeds & 1.26 & 2 & 0.533 \\
Season $\times$ Number of seeds & 0.99 & 1 & 0.320
\end{tabular}

Deviance explained: 40.8\%; Dispersion: 0.73; AIC: 396.7.

plant species is particularly surprisingly for deer, though it could be explained by the large standard error in the percentages of undamaged seeds across faecal samples. As a whole, these results suggest that the sign of the interaction between mammals and fleshy-fruited shrubs was relatively consistent for all species but for rabbit and, perhaps, also for deer.

\section{Discussion}

\section{Overall patterns across frugivores}

As hypothesized based on previous research (Bronstein 1994, Agrawal et al. 2007, Holland and DeAngelis 2009), we found that the strength and sign of the interactions between target plants and frugivores was highly variable in time, space, and with the identities of interacting species. In particular, when applicable, the effectiveness as seed disperser of each frugivore was highly variable in space and time. Thus, seed dispersal of fleshy-fruited plants by mammals in our

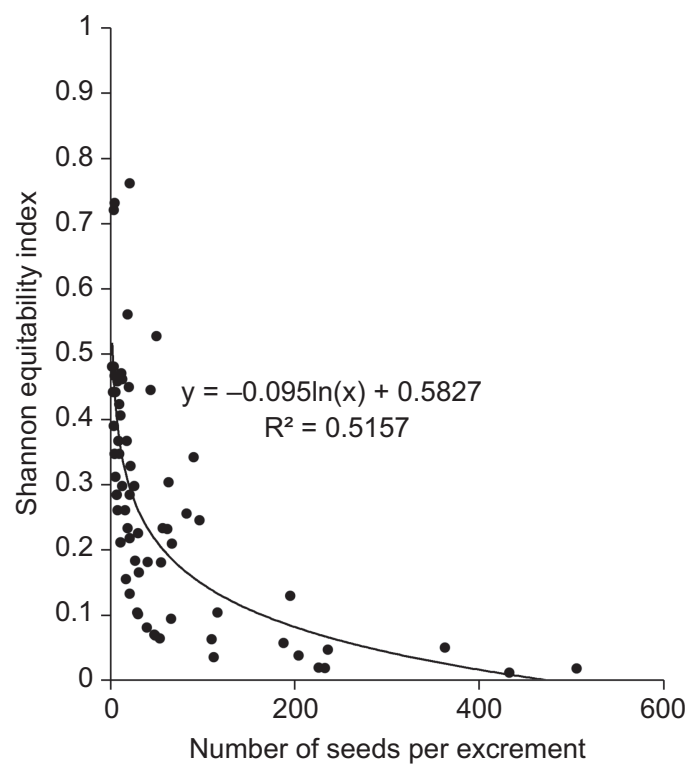

Figure 3. Seed diversity in relationship to number of seeds per faeces. Seed diversity for each faeces was obtained as the Shannon equitability index. Data only for faecal samples containing seeds of more than one plant species. 


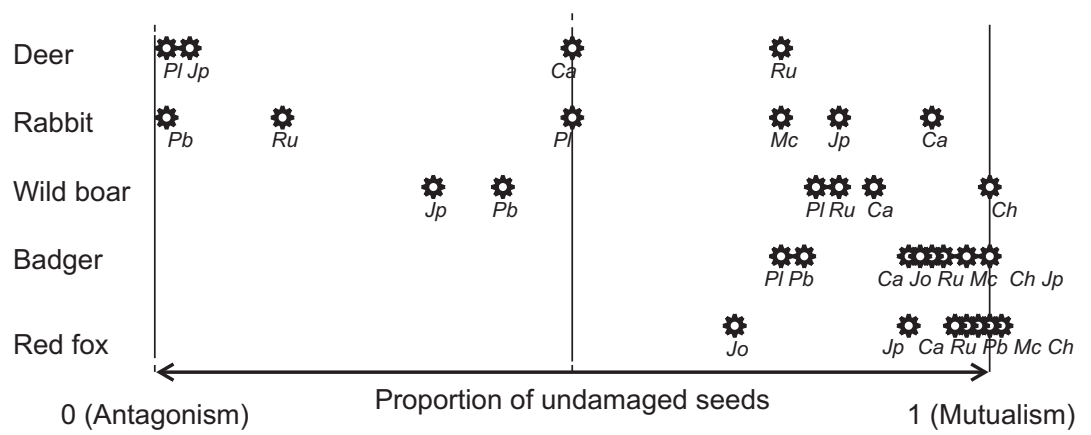

Figure 4. Representation of the 31 fruit-frugivore studied pairs along the mutualism-antagonism continuum. Each asterisk indicates the proportion of undamaged seeds for a specific plant-mammal interaction. We assumed that for pairs of interacting species with low proportion of undamaged seeds the nature of the interaction is mostly antagonistic whereas for pairs of interacting species with high proportion of undamaged seeds the nature of the interaction is mostly mutualistic. Intermediate values (say, 0.4-0.6) would indicate a mixture of antagonism and mutualism whose net effect is likely context-dependent. $C a=C$. album; Ch=C. humilis; Jo=J. oxycedrus; $J p=J$. phoenicea $M c=M$. communis; $P b=P$. bourgaeana; $P l=P$. lentiscus; $R u=R$. ulmifolius.

Mediterranean environment seems to be a highly generalized process involving contrasting mammal species, which strongly differ in crucial traits (e.g. frequency of seed occurrence, seed treatment, defecation rates, faecal marking, dispersal distances, population density, etc.). Moreover, the interaction sign for each mammal species (estimation based on seed treatment) was determined by the identities of interacting species, as predicted. For instance, carnivores damaged only a small proportion of ingested seeds, irrespective of the plant species (Table 1, Fig. 4); wild boar showed an intermediate seed treatment but one that, as for carnivores, was consistent across plant species. Deer destroyed about half of ingested seeds, being the vector closer to the antagonism endpoint along the mutualism-antagonism continuum. For rabbit, however, the seed treatment was dependent on the partner identities, acting mostly as seed disperser for some fruit-bearing plants (e.g. C. album) and mostly as seed predator for some others (e.g. P. bourgaeana and R. ulmifolius).

Though in most cases mammals acted mainly as dispersers, they qualitatively differed in the number of undamaged seeds moved. To attain a precise estimate of the dispersal quantity of each mammal species at the plant community level (mammals overlapped widely in the seed species they ingested; Fig. 4), frequency of seed occurrence, defecation rate, and mammal density should be considered. Taking into account the defecation rates of target dispersers (Briedermann 1971, Tottewitz et al. 1996, Webbon et al. 2004, González-Redondo 2009), a deer in Dońana would disperse, on average, around 29 seeds of fleshy-fruited species per day during the dispersal season, a rabbit 112 seeds day ${ }^{-1}$, a wild boar 465 seeds day ${ }^{-1}$ and a red fox 3786 seeds day ${ }^{-1}$. Badger defecation rate was not available in the literature but, assuming similar defecation rates as foxes, badgers might even disperse more seeds than foxes (around 4615 seeds day ${ }^{-1}$ during the dispersal season). Interestingly, however, when considering the density estimation of each disperser species in the Doñana area (Fedriani and Delibes 2009b), rabbit would reach the highest average dispersal quantity $(22400$ seeds day ${ }^{-1} \mathrm{~km}^{-2}$ during the dispersal season) as opposed to deer, with the lowest value (1566 seeds day ${ }^{-1} \mathrm{~km}^{-2}$ ). Badger, fox and wild boar would show similar and intermediate dispersal quantities $\left(2307,2461\right.$ and 2511 seeds day ${ }^{-1} \mathrm{~km}^{-2}$, respectively). Thus, these estimates suggest that seed dispersal quantities are not necessarily correlated at individual and population levels, in line with findings by Carlo et al. (2003) for a plant-bird network.

Nonetheless, an assessment of dispersal effectiveness requires that qualitative aspects other than seed treatment (e.g. dispersal pattern and distance) are also accounted for (Schupp et al. 2010). For instance, though badgers generally treat seeds gently, they usually deposit a high number of seed per faeces (Table 1) and deposit their faeces in latrines containing several droppings (Hutchings et al. 2001). This fact could enhance seed competition and reduce the probability of successful establishment and, thus, the overall dispersal quality (Spiegel and Nathan 2012). Conversely, foxes deliver their faeces scattered, which could augment their dispersal effectiveness. Furthermore, target mammals strongly differ in their mobility and foraging behavior, likely leading to contrasting dispersal distances. Whereas a rabbit usually moves far less than $1 \mathrm{~km} \mathrm{day}^{-1}$ (Moreno et al. 2004), a wild boar can move over $20 \mathrm{~km}^{-1}$ day $^{-1}$ (on average, 2-16 $\mathrm{km}$ a day; Spitz and Janeau 1990), a red fox about 7-9 km day $^{-1}$ (Servin et al. 1991), and a badger about 4-6 km day ${ }^{-1}$ (Revilla and Palomares 2002). Manipulative studies examining the combined consequences of dispersal distance and seed packing on dispersal effectiveness are certainly needed.

\section{Spatial and temporal variations}

However, as we emphasized, the average values are only gross approaches to the dispersal service even at the local scale of our study. Indeed, our results revealed that frequency of seed occurrence and number of seeds per faecal sample strongly varied among sites, between years, and among plant species. Furthermore, for all mammal species, the frequency of occurrence and number of seed per faecal sample was inconsistent across plant species and sites. These variations clearly suggest that the quantity component of seed dispersal is not species-specific but context-dependent (e.g. local plant community, availability of fruit, etc.), as proposed by Schupp et al. (2010). Furthermore, all studied mammals ingested a 
high variety of fruit species, probably due to their opportunistic behavior, leading to a lack of specificity in our plantfrugivore network. Lack of specificity indicates the absence of highly specialized mutualisms and leads to multi-species interactions, which enhance resilience to unforeseeable environmental changes (Peterson 2000, Frost et al. 1995). This is especially relevant under highly unpredictable weather conditions and disturbances (droughts, fires, floods) such as those typical of Mediterranean ecosystems (Thompson 2005, Pugnaire and Valladares 2007). Consequently, endozoochores seem to ensure various available dispersers which, in addition to varying in their seed treatment, will also vary in their dispersal quantity depending on the environmental context. In this way, endozoochores are likely to spread the risk of a completely inappropriate seed treatment increasing the probability of a partially successful dispersal whatever conditions prevail. This pattern resembles a bet-hedging strategy (Simons 2007) and has been predicted by network theory (Jordano et al. 2003, Bascompte and Jordano 2007, Carlo and Yang 2011).

Interestingly, seed diversity per faecal sample was spatially and temporally consistent for each mammal species. Seed diversity within a faeces is an important and overlooked aspect of seed dispersal effectiveness (but see Jaroszewic et al. 2009, Tsuji et al. 2011). For instance, chemical exudations from germinating seeds can be used as cues to accelerate, delay or even impede germination by conspecific or heterospecific seeds (Loiselle 1990, Warrag 1994, Murray 1998). The negative relationship between the number of seeds per faecal sample and seed diversity (Fig. 3) is probably related with the opportunistic behavior of the studied mammals (low specificity), consuming the most abundant and accessible seed species during a feeding bout, reducing the proportion of other seed species and, therefore, increasing the intraspecific seed competition in faeces. This also suggests higher interaction strength for the most abundant species as seed diversity in faeces decreases. However, such pattern should be considered with caution since frequency of occurrence in faeces and interaction strength may not always correlate well. Experimental studies manipulating faecal seed density and diversity to comprehensively assess their outcomes for seed dispersal effectiveness in different spatial and temporal contexts would be particularly valuable.

Mutualisms are typically characterized by costs and benefits that are highly contingent on the community context in which they are embedded (Bronstein 1994, Agrawal et al. 2007, Holland and DeAngelis 2009, Fedriani et al. 2012). This study revealed important variation in the sign and size of interaction strengths, depending upon the particular species make-up of pairwise plant-frugivore interactions as well as on the spatial and temporal context. Our conclusion therefore supports the most accepted idea of context dependence of species interactions, rather than the results of recent meta-analyses (Karst et al. 2008, Chamberlain and Holland 2009). We call for experimental studies that control for potential correlation among factors and provide estimates of interaction strengths for contrasting mutualisms. We predict that results from such approaches will also support the context dependence of mutualistic interactions.
Acknowledgements - We are indebted to Gemma Calvo, Mónica Váz and innumerable volunteers for their intensive field and lab assistance. We sincerely thank the staff of the National Park Service and of Doñana Biological Station, in particular Sofía Conradi, for their invaluable support along different stages of our study. We are very grateful to Eugene W. Schupp and Tomás A. Carlo for their helpful comments and English corrections. The Spanish Ministry of Environment (15/2003 grant) and the Ministry of Education and Science (CGL2007-63488/BOS) supported this study.

\section{References}

Agrawal, A. A. et al. 2007. Filling key gaps in population and community ecology. - Front. Ecol. Environ. 5: 145-152.

Bascompte, J. and Jordano, P. 2007. The structure of plant-animal mutualistic networks: the architecture of biodiversity. - Annu. Rev. Ecol. Evol. Syst. 38: 567-593.

Begon, M. et al. 1996. Ecology, 3rd ed. - Blackwell.

Berlow, E. L. et al. 2004. Interaction strengths in food webs: issues and opportunities. - J. Anim. Ecol. 73: 585-598.

Briedermann, L. 1971. Ermittlungen zur Aktivitätsperiodik des Mitteleuropäiischen Wildschweines (Sus s. scrofa L.). - Zool. Garten 40: 302-327.

Brodie, J. F. et al. 2009. Functional differences within a guild of tropical mammalian frugivores. - Ecology 90: 688-698.

Bronstein, J. L. 1994. Conditional outcomes of mutualistic interactions. - Trends Ecol. Evol. 9: 214-217.

Carlo, T. A. and Yang, S. 2011. From frugivory to seed dispersal networks: challenges and opportunities of a new paradigm. - Acta Oecol. 27: 619-624.

Carlo, T. A. et al. 2003. Avian fruit preferences across a Puerto Rican forested landscape: pattern consistency and implications for seed removal. - Oecologia 134: 119-131.

Carlo, T. A. et al. 2007. Plant-frugivore interactions as spatially explicit networks: integrating frugivore foraging with fruiting plant spatial patterns. - In: Dennis, A. J. et al. (eds), Seed dispersal: theory and its application in a changing world. CABI, pp. 369-390.

Chamberlain, S. C. and Holland, J. N. 2009. Quantitative synthesis of context dependency in ant-plant protection mutualisms. - Ecology 90: 2384-2392.

Crawley, M. J. 2007. The R book. - Wiley.

Delibes, M. 1980. Feeding ecology of the Spanish lynx in the Coto Doñana. - Acta Theriol. 25: 309-324.

Dennis, A. J. et al. 2007. Seed dispersal: theory and its application in a changing world. - CABI.

Fedriani, J. M. and Delibes, M. 2009a. Functional diversity in fruit-frugivore interactions: a field experiment with Mediterranean mammals. - Ecography 32: 983-992.

Fedriani, J. M. and Delibes, M. 2009b. Seed dispersal in the Iberian pear Pyrus bourgaeana: a role for infrequent mutualists. - Ecoscience 16: 211-221.

Fedriani, J. M. et al. 2010. Spatial pattern of adult trees and the mammal-generated seed rain in the Iberian pear. - Ecography 33: $545-555$.

Fedriani, J. M. et al. 2012. Thieves or mutualists? Pulp feeders enhance endozoochore local recruitment. - Ecology 93: 575-587.

Frost, T. et al. 1995. Species compensation and complementarity in ecosystem function. - In: Jones, C. and Lawton, J. (eds), Linking species and ecosystems. Chapman and Hall, pp. 224-239.

González-Redondo, P. 2009. Number of faecal pellets dropped daily by the wild rabbit (Oryctolagus cuniculus). - J. Anim. Vet. Adv. 8: 2635-2637.

Hampe, A. et al. 2008. Spatio-temporal dynamics and local hotspots of initial recruitment of vertebrate-dispersed trees. - J. Ecol. 96: 668-678. 
Herrera, C. M. 1989. Frugivory and seed dispersal by carnivorous mammals, and associated fruit characteristics, in undisturbed Mediterranean habitats. - Oikos 55: 250-262.

Herrera, C. M. 2002. Seed dispersal by vertebrates. - In: Herrera, C. M. and Pellmyr, O. (eds), Plant-animal interactions: an evolutionary approach. Blackwell, pp. 185-208.

Holland, J. N. and Bronstein, J. L. 2008. Mutualism. - In: Jorgensen, S. E. and Fath, B. D. (eds), Population dynamics, Vol. 3 of Encyclopedia of ecology. Elsevier, pp. 2485-2491.

Holland, J. N. and DeAngelis, D. L. 2009. Consumer-resource theory predicts dynamic transitions between outcomes of interspecific interactions. - Ecol. Lett. 12: 1357-1366.

Howe, H. F. and Smallwood, J. 1982. Ecology of seed dispersal. - Annu. Rev. Ecol. Syst. 13: 201-228.

Hutchings, M. R. et al. 2001. Defecation and urination patterns of badgers Meles meles at low density in south west England. - Acta Theriol. 46: 87-96.

Jaroszewicz, B. et al. 2009. Endozoochory by European bison (Bison bonasus) in Bialowieza Primeval Forest across a management gradient. - For. Ecol. Manage. 258: 11-17.

Jordano, P. 1984. Seed weight variation and differential avian dispersal in blackberries Rubus ulmifolius. - Oikos 43: 149-153.

Jordano, P. 1994. Spatial and temporal variation in the avianfrugivore assemblage of Prunus mahaleb - patterns and consequences. - Oikos 71: 479-491.

Jordano, P. 2007. FRUBASE Ver. 4.0. - < http://ebd10.ebd.csic. es/mywork/frubase/frubase $>$.

Jordano, P. et al. 2003. Invariant properties in coevolutionary networks of plant-animal interactions. - Ecol. Lett. 6: 69-81.

Jordano, P. et al. 2007. Differential contribution of frugivores to complex seed dispersal patterns. - Proc. Natl Acad. Sci. USA 104: 3278-3282.

Jordano, P. et al. 2011. Frugivores and seed dispersal: mechanisms and consequences for biodiversity of a key ecological interaction. - Biol. Lett. 7: 321-323.

Karst, J. et al. 2008. The mutualism-parasitism continuum in ectomycorrhizas: a quantitative assessment using meta-analysis. - Ecology 89: 1032-1042.

Laska, M. S. and Wootton, J. T. 1998. Theoretical concepts and empirical approaches to measuring interaction strength. - Ecology 79: 461-476.

Levey, D. J. et al. 2002. Seed dispersal and frugivory: ecology, evolution and conservation. - CABI.

Loiselle, B. A. 1990. Seeds in droppings of tropical fruit eating birds: importance of considering seed composition. - Oecologia 82: 494-500.

Matías, L. et al. 2010. Seed dispersal patterns by large frugivorous mammals in a degraded mosaic landscape. - Restor. Ecol. 18: 619-627.

Moreno, S. et al. 2004. Wild rabbit restocking for predator conservation in Spain. - Biol. Conserv. 118: 183-193.

Murray, B. R. 1998. Density-dependent germination and the role of seed leachate. - Aust. J. Ecol. 23: 411-418.

Murray, K. G. et al. 1994. Fruit laxatives and seed passage rates in frugivores - consequences for plant reproductive success. - Ecology 75: 989-994.

Palomares, F. and Delibes, M. 1991. Alimentación del meloncillo Herpestes ichneumon y de la gineta Genetta genetta en la Reserva Biológica de Doñana, SO. de la Península Ibérica. - Doñana, Acta Vertebrata 18: 5-20.

Perea, R. et al. 2011. Disentangling factors controlling fruit and seed removal by rodents in temperate forests. - Seed Sci. Res. 21: $227-234$.
Peterson, G. D. 2000. Scaling ecological dynamics: selforganization, hierarchical structure, and ecological resilience. - Climate Change 44: 291-309.

Pugnaire, F. I. and Valladares, F. 2007. Functional plant ecology. - CRC Press.

Revilla, E. and Palomares, F. 2002. Spatial organization, group living and ecological correlates in low-density populations of Eurasian badgers, Meles meles. - J. Anim. Ecol. 71: 497-512.

Schupp, E. W. 1993. Quantity, quality and the effectiveness of seed dispersal by animals. - Vegetatio 108: 15-29.

Schupp, E. W. et al. 2010. Seed dispersal effectiveness revisited: a conceptual review. - New Phytol. 188: 333-353.

Servin, J. et al. 1991. Activity pattern of the red fox Vulpes vulpes in Doñana, SW Spain. - Acta Theriol. 36: 369-373.

Simons, A. M. 2007. Selection for increased allocation to offspring number under environmental unpredictability. - J. Evol. Biol. 20: 813-817.

Spiegel, O. and Nathan, R. 2012. Empirical evaluation of directed dispersal and density-dependent effects across successive recruitment phases. - J. Ecol. 100: 392-404.

Spitz, F. and Janeau, G. 1990. Spatial strategies: an attempt to classify daily movements of wild boar. - Acta Theriol. 35: 129-149.

Thompson, J. D. 2005. Plant evolution in the Mediterranean. - Oxford Univ. Press.

Thompson, J. N. et al. 2001. Frontiers of ecology. - Bioscience 51: $15-24$.

Tottewitz, F. et al. 1996. Counting droppings as a method of estimating the population of ruminant game. - Z Jagdwissenschaft 42: 111-122.

Traveset, A. and Verdú, M. 2002. A meta-analysis of the effect of gut treatment on seed germination. - In: Levey, D. J. et al. (eds), Seed dispersal and frugivory: ecology, evolution and conservation. CABI, pp. 339-350.

Traveset, A. et al. 2001. Passage through bird guts causes interspecific differences in seed germination characteristics. - Funct. Ecol. 15: 669-675.

Traveset, A. et al. 2008. Seed trait changes in dispersers' guts and consequences for germination and seedling growth. - Ecology 89: 95-106.

Tsuji, Y. et al. 2011. The role of Japanese macaques (Macaca fuscata) as endozoochorous seed dispersers on Kinkazan Island, northern Japan. - Mamm. Biol. 76: 525-533.

Vázquez, D. P. et al. 2005. Interaction frequency as a surrogate for the total effect of animal mutualists on plants. - Ecol. Lett. 8: $1088-1094$.

Verdú, M. and Traveset, A. 2004. Bridging meta-analysis and the comparative method: a test of seed size effect on germination after frugivores' gut passage. - Oecologia 138: 414-418.

Wang, B. C. and Smith, T. B. 2002. Closing the seed dispersal loop. - Trends Ecol. Evol. 17: 379-385.

Warrag, M. O. A. 1994. Autotoxicity of mesquite (Prosopis juliflora) pericarps on seed germination and seedling growth. - J. Arid. Environ. 27: 79-84.

Webbon, C. C. et al. 2004. Faecal density counts for monitoring changes in red fox numbers in rural Britain. - J. Appl. Ecol. 41: 768-779.

Wootton, J. T. and Emmerson, M. 2005. Measurement of interaction strength in nature. - Annu. Rev. Ecol. Evol. Syst. 36: 419-444.

Zuur, A. F. et al. 2009. Mixed effects models and extensions in ecology with R. - Springer. 